\title{
Sigmoide Volvulus on Pregnancy in the General Surgery Service of the Sikasso Hospital, Mali
}

\author{
A. Maïga 1*, T. Bathio², M. Diassana², I. Diakité1, A. Bah1, A. B. Diallo², A. A. Traoré1, M. Diallo³, \\ B. T. Dembélé1, B. Y. Sidibé1, O. H. Saadé1, M. Kanté², M. Konaté1, S. Dembélé1, M. Samaké1, \\ A. Togo' ${ }^{1}$ A. Traoré ${ }^{1}$, G. Diallo ${ }^{1}$
}

${ }^{1}$ Service of General Surgery, Teaching Hospital, Bamako, Mali

${ }^{2}$ Service of General Surgery, Hospital of Sikasso, Sikasso, Mali

${ }^{3}$ Reference Heath Center of Commune VI, Bamako, Mali

Email: *amadoumaiga3@gmail.com

How to cite this paper: Maiga, A., Bathio, T., Diassana, M., Diakité, I., Bah, A., Diallo, A.B., Traoré, A.A., Diallo, M., Dembélé, B.T., Sidibé, B.Y., Saadé, O.H., Kanté, M., Konaté, M., Dembélé, S., Samaké, M., Togo, A., Traoré, A. and Diallo, G. (2019) Sigmoide Volvulus on Pregnancy in the General Surgery Service of the Sikasso Hospital, Mali. Surgical Science, 10, 229-234. https://doi.org/10.4236/ss.2019.107025

Received: May 21, 2019

Accepted: July 22, 2019

Published: July 25, 2019

Copyright $\odot 2019$ by author(s) and Scientific Research Publishing Inc. This work is licensed under the Creative Commons Attribution International License (CC BY 4.0).

http://creativecommons.org/licenses/by/4.0/

\begin{abstract}
Sigmoid volvulus on pregnancy is a rare surgical emergency. We report two cases treated in the General Surgery Department of Sikasso Hospital between January 2009 and December 2017. The mean age was 34.8 years and the gestational age ranged from 28 to 30 weeks. The evolution time was 4 days. The 2 patients were referred to us by gynecologist-obstetricians. They were operated after a short-term resuscitation. Inoperative the volvulus of the sigmoid was alone in 1 case; he was associated with a hail volvulus in the other. The volvated loop was necrotic in 1 case (small and sigmoid). A patient benefited from the Hartmann operation associated with a small bowel resection with end-to-end anastomosis. Simple sigmoidal detorsion was performed in one patient. We did not register a maternal death. The follow-up was simple in the 2 patients who gave birth vaginally.
\end{abstract}

\section{Keywords}

Sigmoid Volvulus, Surgical Emergency, Pregnancy

\section{Introduction}

The sigmoid volvulus can occur on particular as pregnancy where it constitutes the second cause of occlusion after flange occlusion [1]. It is a serious digestive emergency with a high-risk maternal fetal age due to delayed diagnosis, made of its rarity and especially modifications during pregnancy [2]. Taking in charge is multidisciplinary. The mother's life passes always before that of the fetus [3].

We report two cases of sigmoid volvulus on pregnancy treated in the surgery 
department of the Sikasso Hospital between January 2009 and December 2017.

\section{Case Report}

They have been expressed as clinical cases.

\subsection{Observation $\mathrm{N}^{\circ} \mathrm{I}$}

Ms. F., aged 32, with no background particular pathological conditions, was sent by the obstetric gynecologist for abdominal pain on pregnancy of 30 SA. This pain was associated with postprandial vomiting late, a stoppage of materials and gases for 3 days. At admission the general condition was good, the temperature at $37^{\circ} \mathrm{C}$, the pulse $=98$ beats $/ \mathrm{min}$, the blood pressure was $130 / 80 \mathrm{mmHg}$. Examination has shown abdominal asymmetry the inspection, a diffuse pain all over the abdomen without defense, uterine height to $20 \mathrm{~cm}$. Percussion found a tympanism in the epigastrium and the left hypochondrium. An accentuation of the noiseshydro-aerials was found at the auscultation, the Fetal heart sounds were regular at 144 beats/min. With the vaginal touch, the cervix was long, posterior and closed. The rectal bulb was empty at Rectal touch.

The abdominopelvic ultrasound showed a digestive distension with intravenous effusion peritoneal associated with intrauterine pregnancyscalable of 30SA (Figure 1: volvulus on pregnancy ultrasound).

The diagnosis of intestinal obstruction on pregnancy has been retained, imposing a laparotomy. Exploration has highlighted: a pregnant uterus, a very distended sigmoidal loop volvated to a turn of turn clockwise without necrosis (Figure 2: volvulus on pregnancy without necrosis). There was a fluid effusion of $100 \mathrm{cc}$ we have aspirated. We performed a sigmoidal detorsion more peritoneal toilet with saline serum and closing of the abdominal cavity.

The suites were simple. The patient gave birth bylane 45 days later from a newborn to term in which the examination was normal.

\subsection{Observation $\mathrm{N}^{\circ} 2$}

Ms. F.D., 30 years old, was sent to the emergency room by the Kadiolo health

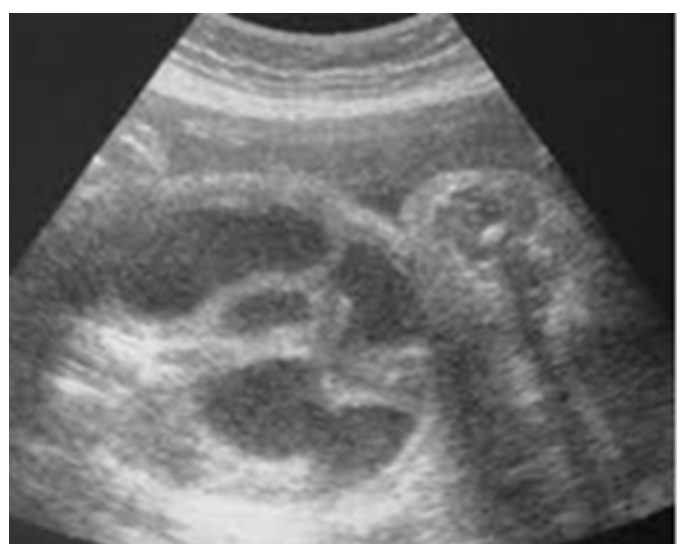

Figure 1. Volvulus on pregnancy ultrasoundcase 1. 


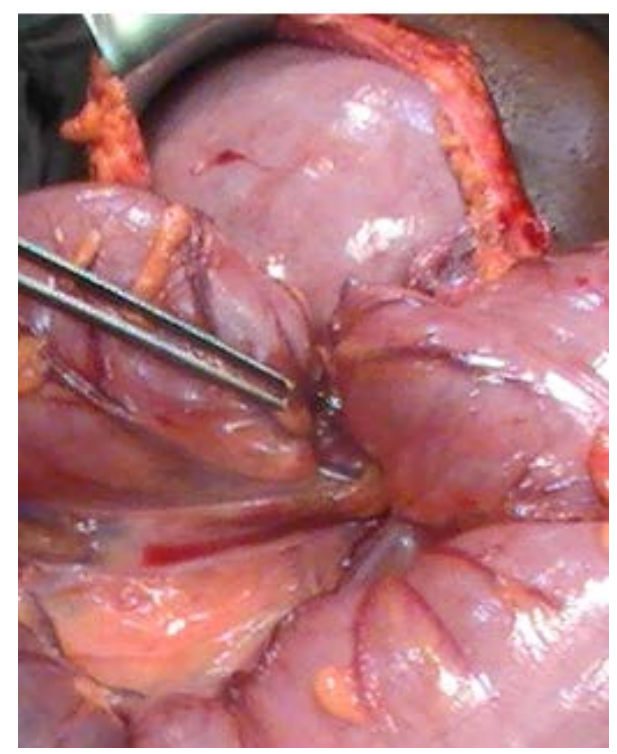

Figure 2. Volvulus on pregnancy without necrosis case 1 .

center for occlusive syndrome.

The beginning went back to 4 days by a brutal pain peri-umbilical associated with vomiting and stopping materials and gases in a context of amenorrhea 28 weeks. The examination found a Karnovski $70 \%$ with fever at $39.3^{\circ} \mathrm{C}$, tension at $100 / 60 \mathrm{~mm} \mathrm{Hg}$, a pulse of 112 beats/min and a frequency respiratory rate of 28 cycles/min. the abdomen increased volume and asymmetrical carries a scar under medial umbilical. At the palpation, there was a diffuse abdominal pain with defense. Examination gynecological highlighted a uterus increased by size, a long neck of $2 \mathrm{~cm}$ closed median and whitish leucorrhoea brought back by the fingerstall. The touched rectally, the Douglas was bulging and painful, the empty rectal ampoule.

$\mathrm{X}$-ray of the abdomen without preparation has objectified a girder arch double jamb repressed upwards by uterine opacity (Figure 3: ASP double jamb image). Ultrasound showed a significant digestive distension associated with intraperitoneal effusion and pregnancy evolutionary 28 weeks. The diagnosis of peritonitis on pregnancy was retained thus imposing a surgical exploration. The median laparotomy above and under umbilical has shown: an effusion sero $200 \mathrm{cc}$, a necrotic sigmoid loop volvated in 2 turns of turns clockwise, and necrosis of the hail, a pregnant uterus (Figure 4: volvulus on pregnancy with necrosis).

We proceed to a suction of liquid, a Resection of the small bowel with end-to-end anastomosis.

A sigmoidectomy followed by a colostomy.

Hartmann. The postoperative course was simple after the operation. The patient gave birth by lane two months later from a newborn to term.

Restoration of continuity has been achieved. Six months later, the aftermath of the recovery was simple. 


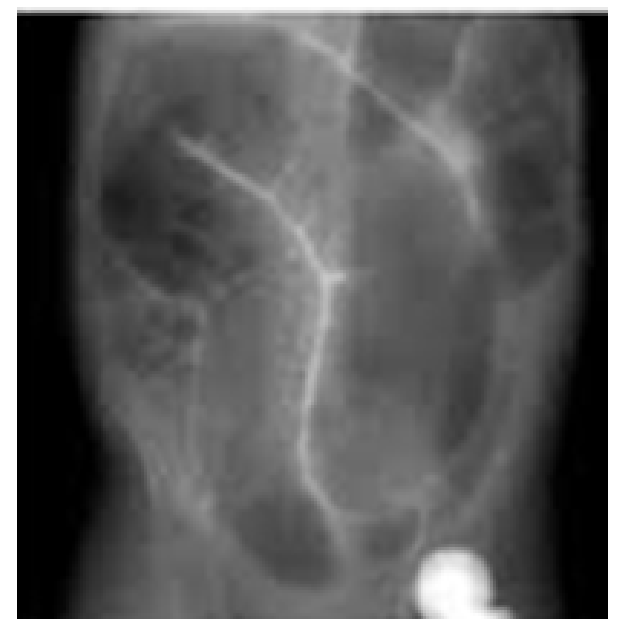

Figure 3. ASP double jamb image case 2.

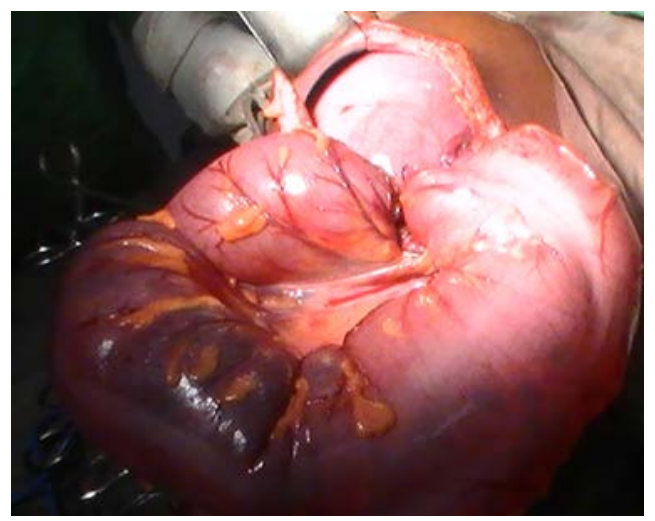

Figure 4. Volvulus on pregnancy with necrosis case 2 .

\subsection{Comment}

The frequency of pregnancy occlusion is estimated at $1 / 3600$ pregnancies; the main reported causes were the flanges and the volvulus of the sigmoid [4].

Intestinal occlusion by sigmoid volvulus is very rare during pregnancy [5]. In 8 years we found 2 cases. According to Khanna (India) in 1999 only 73 cases have been reported in the literature world [1] and Chourak (Morocco) in 2009 found 76 cases of volvulus on pregnancy in the world [2]. The gestational age of our patients ranged from 28 to $30 \mathrm{SA}$ which is comparable to 22 - 38 S.A. de literature [5] [6] [7]. Many authors have made a relationship between the means of attachment of the sigmoid and the volvulus [6] [7].

The 4-day consultation period of our study was Twice as long as that of Goundo (2006) who had does his work on sigmoid volvulus in general [8].

This could be explained by the difficulty of diagnosis of intestinal obstruction during pregnancy the signs are falsely attributed to a threat premature delivery.

The clinical diagnosis is based on the triad: pain, stopping of materials and gases, vomiting and physical signs. Biological signs are not specific. Ultrasound allows to objectify a digestive distension, intraperitoneal effusion and a pregnant 
uterus specifying the age of pregnancy and fetus vitality according to Musoke (Uganda) the first intension examination [9]. But this is the X-ray of the abdomen without preparation which breaks the positive diagnosis of volvulus, the fear of irradiation of some authors remains unfounded because it takes ten times the dose an ASP to have 0.01 Gray that is the dose with a congenital malformation risk of $1 / 1000$ [3].

Treatment consists in lifting the obstacle, avoiding the recurrence, allowing the pregnancy to progress to term if possible; in any case the mother's life is the priority. All our patients benefited fromtocolysis, from a resuscitation of $30 \mathrm{mi}$ nutes to 2 hours.

According to Twité [3], the management of an occlusion on Pregnancy requires essential rehydration to ensure uterine blood flow and maintain the fetal vitality. Surgical treatment was the resection plus Hartmann-type colostomy once.

This technique was the most used according to the literature [10] [11] [12] despite having rare cases of remissions pontaneous reported by $\mathrm{De} U$ in India [11]. This attitude is explained by the delayed diagnosis and therapeutic that results in local conditions (necrosis, unprepared colon) and general preventing endoscopic detorsion. In all cases, the gesture minimum would increase the chance of having suites simple operatives for the mother and the fetus [13].

The operative sequences were simple in both cases, they gave birth normally.

We did not have any maternal or fetal deaths.

Wamoto in Japan also reported a death case in utero fetal and maternal death postoperatively immediate [14]. Fetal mortality is close to zero in the first quarter, it is $36 \%$ and $64 \%$ respectively in the second and third quarters of pregnancy $[3]$.

\section{Conclusion}

The sigmoid volvulus on pregnancy is an entityrare and its care is multidisciplinary. Early diagnosis and management could improve the maternal-fetal prognosis.

\section{Conflicts of Interest}

The authors declare no conflicts of interest regarding the publication of this paper.

\section{References}

[1] Khanna, A., Kumar, P. and Khanna, R. (1999) Sigmoid Volvulus: A Study from a North Indian Hospital. Diseases of the Colon \& Rectum, 42, 1081-1084. https://doi.org/10.1007/BF02236708

[2] Chourak, M., Beavogui, L., Lachkar, A. and Elabsi, M. (2009) Volvulus dusigmoïde nécrosé chez une femme enceinte. Journal Africain d Hépato-Gastroentérologie, 3, 35-37. https://doi.org/10.1007/s12157-009-0065-1

[3] Twité, N., Jacquet, C., Hollemaert, C., El Founas, I.T., Dumont, G., Nasr, A., Guch- 
teneere, E. and Busine, A. (2006) Intestinal Obstruction in Pregnancy. Revue Médicale de Bruxelles, 27, 104-109.

[4] Perdue, P.W., Johnson, H.W. and Staffort, P.W. (1992) Intestinal Obstruction Complicating Pregnancy. The American Journal of Surgery, 164, 384-388. https://doi.org/10.1016/S0002-9610(05)80910-9

[5] Alshawi, J.S. (2005) Recurrent Sigmoid Volvulus in Pregnancy: Report of a Case and Review of the Literature. Diseases of the Colon \& Rectum, 48, 1811-1813. https://doi.org/10.1007/s10350-005-0118-5

[6] Dufour, P., Haent, K., Vinatier, D., Tordjeman, N., Monnier, J.C. and Puech, F. (1996) Occlusion during Pregnancy: 7 Cases Report. The European Journal of Obstetrics \& Gynecology and Reproductive Biology, 25, 297-300.

[7] Lord, S.A., Boswell, W.C. and Hungerpiller, J.C. (1996) Sigmoid Volvulus in Pregnancy. The American Surgeon, 62, 380-382.

[8] Goundo, D.Y. (2006) Volvulus du sigmoïde à l'hôpital Gabriel Touré. Médecine Thèse, Université de Bamako, Bamako.

[9] Musoke, F., Kawooya, M.G. and Kiguli-Malwadde, E. (2003) Comparison between Sonographic and Plain Radiography in the Diagnosis of Small Bowel Obstruction at Mulago Hospital, Uganda. East African Medical Journal, 80, 540-545. https://doi.org/10.4314/eamj.v80i10.8758

[10] Joshi, M.A., Balsarkar, D., Avasare, N., Pradhan, C., Perira, G., Subramanyan, P., Shirahatti, R.G. and Changlani, T.T. (1999) Gangrenous Sigmoid Volvulus in a Pregnant Woman. Tropical Gastroenterology, 20, 141-142.

[11] Narjis, Y., Mansouri, M.N., Jgounni, R., Louzi, A., Abassi, H., Soumani, A., Benclkhayat, R., Finech, B. and Idrissi, A. (2008) Volvulus dusigmoïde une complication rare de la grossesse. Gynécologie Obstétrique \& Fertilité, 36, 776-778. https://doi.org/10.1016/j.gyobfe.2008.05.004

[12] De, U. and De, K.K. (2005) Sigmoid Volvulus, Complicating Pregnancy. Indian Journal of Medical Sciences, 59, 317-319. https://doi.org/10.4103/0019-5359.16507

[13] Hof, G.L. and Sonnen, W.W. (1985) Sigmoid Volvulus in Advanced Pregnancy: Report of 2 Cases. South African Medical Journal, 67, 63-64.

[14] Wamoto, I., Miwa, K., Fujino, T. and Douchi, T. (2007) Perforated Colon Volvulus Coiling around the Uterus in a Pregnant Woman with a History of Severe Constipation. Journal of Obstetrics and Gynaecology Research, 33, 731-733. https://doi.org/10.1111/j.1447-0756.2007.00641.x 